\title{
Lixões inativos na região carbonífera de Santa Catarina: análise dos riscos à saúde pública e ao meio ambiente
}

\author{
Inactive dumps in Santa Catarina's carboniferous area: \\ analysis of risks to the public health and the environment
}

\author{
Fernando Pagani Possamai ${ }^{1}$ \\ Ednilson Viana ${ }^{2}$ \\ Harry Edmar Schulz ${ }^{3}$ \\ $M$ arcel M adeira de Costa ${ }^{4}$ \\ Everson Casagrande ${ }^{5}$
}

${ }^{1}$ Laboratório de Resíduos Sólidos, Universidade do Extremo Sul Catarinense, UNESC, Avenida

Universitária 1105, Bairro Universitário, 806000

Criciúma SC.

fpossamai@brturbo.com.br

${ }^{2}$ UNESC e Universidade

Federal do Paraná.

${ }^{3}$ Departamento de

Hidráulica e Saneamento

da Escola de Engenharia de

São Carlos, USP.

${ }^{4}$ UNESC.

${ }^{5}$ UNESC.
Abstract The existence of inactive dumps considerably increases the so-called "environmental liability"; so much so that the final destination of urban solid residues takes a prominent place on the list of environmental issues of societies ${ }^{1}$. In the state of Santa Catarina, it can be said that, currently, the real conditions of the "final destination deposits", or simply the inactive dumps, is officially unknown. This is maybe most evident in the carboniferous area of the state that already suffers from the environmental impact of coal mining. This study attempts to make a survey of the inactive dumps in the carboniferous area of Santa Catarina, analysing the risks they represent to public health and to the environment. The results gathered show that, of the eleven municipal districts in the carboniferous area, nine have inactive dumps. In these nine districts, there are eleven inactive dumps that, according to the this evaluation, represent a large risk to public health and the environment when the parameters analysed are taken into acount.

Key words Solid residues, Inactive dumps, Environmental legislation, Remedy
Resumo A existência delixões inativos aumenta consideravelmente 0 assim denominado "passivo ambiental"; tanto que a destinação final dos resíduos sólidos urbanos ocupa lugar primordial na pauta das questões ambientais das sociedades'. No estado deSanta Catarina, pode-seafirmar que, atualmente, éformalmente desconhecido o estado real em que se encontram os "depósitos de destinação final" ou, maissimplesmente, os lixões inativos. Isto é talvez mais evidente na região carbonífera do estado, já tão sacrificada pelos impactos ambientais da mineração do carvão. Este trabaIho buscou realizar um levantamento dos lixões inativos na região carbonífera deSanta Catarina, analisando os riscos que estes representam à saúde pública eao meio ambiente. 0 s resultados obtidos mostram que, dos onze municípios pertencentes à região carbonífera, nove possuem lixões inativos. Nesses nove municípios, há onze lixões inativos que, segundo a presente avaliação, apresentam grande risco à saúde da população e ao meio ambiente quando considerados os parâmetros analisados.

Palavras-chave Resíduos sólidos, Lixõesinativos, Legislação ambiental, Remediação 
Introdução

A Associação dos Municípios da Região Carbonífera (AM REC) ${ }^{2}$ envolve os municípios catarinenses de Cocal do Sul, Criciúma, Forquilhinha, Içara, Lauro M üller, M orro da Fumaça, N ova Ve neza, Orleans, Siderópolis, Treviso e Urussanga ${ }^{3}$. Estes municípios compõem a região carbonífera catarinense, localizada no sul do estado de Santa Catarina ecada um possui um centro urbano homônimo (cidade).

Quanto ao tipo de clima, a região carbonífera se enquadra no clima do grupo C - mesotérmico, uma vez que as temperaturas médias do mês mais frio estão abaixo dos $18^{\circ} \mathrm{C}$ e acima de 3oC. Pertence ao tipo úmido (f), sem estação seca definida, pois há índices pluviométricos inferiores a $60 \mathrm{~mm}$ mensais $\mathrm{s}^{3}$. Segundo dados da $A M R E C^{2}$, o regime de chuvas apresenta precipitações anuais que variam de 1.300 a $1.800 \mathrm{~mm}$. Com relação à estrutura do solo, na região carbonífera as formações geológicas sobrepostas às camadas de carvão são argilo-minerais de excelente qualidade, além das argilas com impurezas, adequadas para a cerâmica vermelha. Essas formações se encontram em todos os municípios da região, segundo Krebs ${ }^{4}$.

$\mathrm{H}$ istoricamente, as cidades pertencentes ao extremo sul do estado de Santa Catarina foram povoadas principalmente por imigrantes europeus, que natural menteadotaram como uma forma de desenvolvimento o uso das riquezas encontradas em abundância naquele ambiente. $\mathrm{Na}$ região carbonífera, o carvão foi a principal fonte impulsionadora do desenvolvimento das cidades, induzindo a evolução dos quadros positivos ou negativos de natureza econômica, social e ambiental nos municípios que a compõe.

O carvão, como fonte de energia, começou a ser consolidado em meados do século XVIII, com a Revolução Industrial ${ }^{2: 5}$ ). Em Santa Catarina, o interesse pela exploração do carvão mineral de forma industrial começou em 1884, com a conclusão da estrada de ferro Dona Tere sa Cristina. Com esse evento, estabeleceu-seuma ligação estratégica entre a Vila Estação das M inas (maistardeemancipada para Cidadede Lauro Müller) e o porto de Imbituba. No ano seguinte, começaram efetivamente as extrações de carvão ${ }^{7}$. A região sul de Santa Catarina passou então a ser denominada de "Bacia Carbonífera de Santa Catarina".

Já na segunda metade do século XX, durante os anos de 1950 a 1960, as minas tornaram-se mecanizadas, com a implantação de modelos de extração americanos e a importação de máquinas americanas. Isto possibilitou a retirada de volumes maiores, em menor tempo e com menor número de trabalhadores.

A contínua perda da qualidade sócio-ambiental na região carbonífera, decorrente do modelo extrativo então adotado, concentrado no rendimento econômico e não considerando os custos sociais e ambientais, atinge hoje proporções alarmantes. Em termos ambientais, é evidentea poluição do sistema hídrico. Avalia-seque dois terços dos recursos hídricos superficiais estão hoje comprometidos, com os rios assoreados e praticamente mortos. Os baixos índices de $\mathrm{pH}$ daságuas (variando de 2 a 3 ) e os seus al tos valores de condutividade estão relacionados com a presença de piritas, decorrentes das argilas sulfurosas e metais pesados, al guns desses últimos teratogênicos e cancerígenos. Evidentemente, há sérios problemas sócio-econômicos, pois o comprometimento da qualidade das águas impede 0 seu uso na irrigação da cultura de arroz, acarreta a mortandade dos peixes para o sustento das famílias que vivem exclusivamente da pesca, e inviabiliza 0 abastecimento de água das cidades. Como exemplo, menciona-se a cidade de Criciúma, que até pouco tempo se utilizava das águas do Rio Mãe Luzia, e que teve de substituir esse provedor, com limitações, pelo Rio São Bento ${ }^{6}$.

$\mathrm{Na}$ extração do carvão mineral, em Santa Catarina, as etapas que contribuem para a degradação ambiental envolvem a lavra, o beneficiamento, a disposição dos rejeitos e o transporte do carvão ${ }^{7}$. Como em todas as atividades extrativistas, na atualidade convive-se com a dualidadeentre aspectos sócio-econômicos (positivos) e ambientais (negativos). A exploração de carvão é, por um lado, fonte de emprego e recursos para a população, e, por outro lado, uma atitude poluente ${ }^{8}$.

Convém mencionar que as características observadas em Santa Catarina não são exclusivas desse estado. Sabe-se que a mineração éuma das atividades humanas que mais contribuem para a alteração da superfície terrestre, afetando tanto 0 ambiente interno, a área minerada, como o externo, provocando expressivosimpactos sobre a água, o ar, o solo, o subsolo e a paisagem como um todo ${ }^{~}$. Contudo, associada ao problema da poluição causada pela própria mineração do carvão, existe, na região, uma situação adicional causadora de grande impacto ambiental. Trata-se da disposição inadequada dos resíduos sólidos.

Sabe-se que o crescimento das concentrações 
urbanas e o avanço tecnológico causaram um aumento substancial da produção e do consumo de bens pela população, gerando, conseqüentemente, uma grande quantidade de resíduos sólidos. Esses resíduos são de diferentes naturezas, sen do freqüentemente depositados de forma inadequada no meio ambiente. Além do aumento dos resíduos, a sua toxidade também está crescendo, havendo maior uso de produtos químicos e de "energias não limpas" na produção de bens, como a energia atômica. Finalmente, ainda nos deparamos com a diminuição ou encarecimento das áreas destinadas aos aterros sanitários, o que contribui para agravar o problema da disposição final ${ }^{10}$. Em outras palavras, é de conhecimento geral ${ }^{11}$ que, além do aumento da quantidade, aumentou-sea complexidadedo lixo, não existindo locais em quantidade suficiente para sua destinação final. Considerando as tecnologias desenvolvidas no contexto da "eliminação do lixo", ou elas são muito caras, como é o caso dos incineradores computadorizados e com filtro, ou são insatisfatórias ambientalmente, como é o caso dos aterros sanitários em uso. Grande partedos atuais aterros sanitários podem ser considerados aterros controlados ou lixões, devido à falta de controle na elaboração ou execução do projeto e devido à desobediência para com as normas legais.

Considerando dados mais atualizados, no Brasil, estima-se que cada brasileiro produza 1,3 quilograma de lixo por dia, o que representa a geração diária de aproximadamente $230 \mathrm{mil}$ toneladas de resíduos ${ }^{12}$.

O gerenciamento dos resíduos sólidos urbanos não tem um manejo seguro enem um efetivo fluxo, pois existem muitos impactos sobre a saúde pública e o meio ambiente. A situação atual dos municípios brasilei ros referente à disposição final dos resíduos sólidos urbanos, segundo Pesquisa Nacional de Saneamento Básico $(\text { IBGE })^{13}$, expõe que: $37,0 \%$ dos resíduos sólidos são depositados em aterros sanitários, $36,2 \%$ são depositados em aterros controlados, 22,5\% em vazadouro a céu aberto (lixão), 2,9\% em estação de compostagem, 1,0\% em estação de triagem, e $0,5 \%$ incinerados ${ }^{14}$.

Os lixões podem ser definidos livremente como a simples descarga de lixo sem qualquer tratamento sobre o solo, sem medidas de proteção ao meio ambiente ou à saúde pública, sendo utilizada na maioria dos municípios ${ }^{15}$.

Causas inocentes, como a falta de opção ou de consciência técnica, ou "menos inocentes", como a má vontade política para resolver a des- tinação final dos resíduos sólidos, fazem com que o lixo seja disposto clandestinamente, causando diretamente poluição do ar, do solo e das águas superficiais e subterrâneas. Considerando a saúde pública, os vetores de doenças são tanto os macrovetores (cachorros, gatos, ratos, urubus, pombos e outros), como os microvetores (moscas, mosquitos, bactérias, fungos e outros) ${ }^{13}$.

Destacando 0 aspecto de poluição das águas, vale lembrar que nos lixões o chorume é um dos principais elementos impactantes, sendo originado da decomposição da matéria orgânica contida no lixo, associada aos líquidos percolados ali existentes ${ }^{16}$. Se o solo sob o lixão for permeável, o chorume poderá atingir o lençol freático, poluindo esse recurso hídrico. A geração de chorume pode alongar-se além de quinze anos após o final da deposição de lixo, dependendo de vários fatores. Um exemplo brasileiro é um aterro na cidade de São Paulo, com mais dequinzeanos, queacumula todos os dias aproximadamente 500 mil litros de chorume ${ }^{17}$. Substâncias químicas encontradas tanto em resíduos industriais como no chorume podem ser assimiladas por vegetais, não sendo recomendada a utilização dessas culturas para al imentação ${ }^{11}$.

Atualmente, deve-se observar determinados requisitos técnicos para a disposição final dos resíduos, visando impedir impactos ao meio ambiente. Segundo Rocca ${ }^{18}$, por exemplo, devem ser observadas distâncias de 10 quilômetros entre o terreno e a área urbana, e afastamentos maiores que 200 metros de corpos de água superficiais, sendo esta última restrição também corroborada pela Norma Técnica N BR $8419{ }^{19}$ e pela N BR $13896{ }^{20}$. Além disso, 0 solo tem que ser de baixa permeabilidade (argiloso), deven do ser construídos poços de monitoramento.

O fim de operação de um lixão não cessa 0 conjunto de problemas que ele pode causar. Como já se mencionou, a geração de chorume, por exemplo, pode continuar ao longo de décadas. São, portanto, necessárias medidas de proteção posteriores ao funcionamento, comumente chamadas de métodos de remediação.

A remediação e o fechamento de lixões objetivam reduzir, o máximo possível, os impactos ambientais negativos decorrentes da deposição inadequada do lixo. Basicamente, encerra-se a operação no local, estabilizam-se os processos (físico-químico-biológicos) que ali ocorrem e busca-se destiná-lo a uma utilização adequada no futuro. 0 período deestabilização geral mentenão é inferior a 10-15 anos após encerramento da 
disposição de lixo. Ainda segundo o IPT/CEM $P R E$, vários são os métodos recomendados para realizar o fechamento e remediação dos lixões inativos. Dentre eles, o modo momentaneamente mais adequado é a retirada da massa de lixo, transpondo-a para um aterro sanitário e recuperando a área escavada com solo natural da região. Porém, os custos envolvidos são elevados. Uma forma atualmente mais econômica para minimizar impactos ambientais na remediação e fechamento dos lixões inativos é uma seqüência de providências, como: a) eliminar fogo efumaça; b) limpar a área; c) providenciar cobertura final; d) drenar águas superficiais; e) drenar 0 biogás e o percolado do lixo; f) coletar e tratar 0 biogás e o percolado; g) efetuar monitoramento geotécnico e ambiental; h) efetuar manutenção das estruturas do aterro; i) elaborar projeto paisagístico e de uso futuro da área.

Sempre convém reafirmar que o gerenciamento dos resíduos sólidos é parte indissociável do desenvolvimento sustentável, cuja finalidade últimaéa de propiciar a todosos indivíduosuma qualidade de vida sadia, perseguindo os preceitos contidos no artigo 225 da Carta Magna ${ }^{21}$.

\section{M ateriais e métodos}

No presentetrabal ho, buscou-se descrever a realidade dos lixões inativos existentes nos municípios da região carbonífera de Santa Catarina, visando estabelecer os riscos eventuais que repre sentam à saúde pública e ao meio ambiente. Foram considerados, na análise, a proximidade de corpos de água superficiais, coleta e tratamento de biogás, coleta e tratamento de chorume, existência de piezômetro e coleta mensal para análise, proximidade de residências, existência de cercas, tipo de cobertura e existência de manta de impermeabilização.

Os municípios envolvidos nesta pesquisa foram: Cocal do Sul, Criciúma, Forquilhinha, Içara, Lauro M üller, M orro da Fumaça, Nova Vene za, Orleans, Siderópolis, Treviso e U russanga. A coleta de dados foi feita na forma de entrevistas, com questionários que continham vinte e cinco questões, considerando, além dos aspectos já mencionados, também a idade, formas de remediação dos lixões, mecanismos legais existentes nos municípios que propiciem condições adequadas de inativação e recuperação dos lixões.

Os questionários foram aplicados aos repre sentantes legais da Secretaria do M eio Ambiente ou às pessoas indicadas pelo município, através de agendamento prévio das entrevistas. 0 pre enchimento dos dados foi feito de forma escrita eindividual. Todas as entrevistas envolviam uma visita ao local do lixão inativo e ao local de disposição atual dos resíduos sólidos. Foram realizadas ainda anotações e registros sobre outras situações relacionadas diretamente aos resíduos sólidos gerados nos municípios, como a existência de catadores nas áreas de disposição final.

Inicialmente, foram definidos parâmetros para auxiliar no estabelecimento do grau de risco dos lixões inativos na região estudada. Posteriormente, foram criados "indicadores de grau de risco", qualificando sua intensidade em "baixo", "regular" e "crítico". Os parâmetros, em número de oito, são indicados a seguir.

1) Proximidadedecorpos deágua superficiais

Os dados foram coletados diretamente no local do lixão inativo utilizando uma trena de 50 metros para conferir as distâncias. Considerando as normas já mencionadas, a distância deve ser maior que 200 metros de qualquer coleção hídrica ou curso de água. No presente trabalho, tendo por base essa distância limite, foram propostos os critérios para classificação do grau de risco, com conotação estritamente geométrica e considerando as águas superficiais: distância acima de 200 metros dos lixões inativos, com grau de risco baixo; distância entre 101 a 200 metros, com grau de risco regular, e distância entre $0 \mathrm{a}$ 100 metros, com a qualificação do grau de risco crítico. N ote-se que este é um critério expedito e objetivo, que utiliza dados visuais. Questões envolvendo a distância a águas subterrâneas exigiriam as características do solo, relativas a permeabilidade, condutividade hidráulica e demais características físicas, além de soldagens que conferem morosidade aos procedimentos.

As normas consideram favoráveis as distâncias acima de 200 metros de corpos de água superficiais, mas evidentemente distâncias menores são observadas e a qualificação do grau de risco deve ser feita no contexto dessa realidade.

2) Coleta e tratamento do biogás

Os dados sobre a presença de coleta e tratamento de biogás foram coletados no momento da entrevista e na visitação ao local do lixão inativo. A verificação in loco sempre foi feita, permitindo a eventual atualização das informações (avarias, ausência de manutenção podem alterar as condições das instalações).

Para este parâmetro, foram propostos graus de risco de acordo com a presença ou ausência dos seguintes procedimentos: realização de coleta etratamento do biogás, com grau de risco bai- 
xo; coleta einexistência detratamento do biogás, com grau de risco regular, einexistência de coleta e tratamento de biogás, com a qualificação com grau de risco crítico.

3) Coleta e tratamento de águas pluviais

Os dados sobre a existência de coleta e tratamento de águas pluviais também foram coletados no momento da entrevista e na visitação ao local do lixão inativo, sendo propostos os graus de risco de acordo com a presença ou ausência dos seguintes procedimentos: realização de coleta ou desvio das águas pluviais, com o devido tratamento das mesmas, com grau de risco baixo; coleta einexistência detratamento das águas pluviais, com grau de risco regular, einexistência de coleta etratamento deáguas pluviais, com a qualificação do grau de risco crítico.

4) Coleta e tratamento do chorume

Os dados sobrea coleta etratamento do chorume também foram coletados no momento da entrevista ena visitação ao local do lixão inativo, sendo propostos os graus de risco de acordo com a utilização de equipamentos para coleta e tratamento do chorume gerado. Foram considerados como indicadores do grau de risco baixo a realização de coleta e o tratamento do chorume; a coleta e inexistência de tratamento do chorume com grau de risco regular, e a inexistência de coleta e tratamento, com a qualificação do grau de risco crítico.

5) Monitoramento nos lixões inativos

Os dados sobre o monitoramento também foram coletados no momento da entrevista e na visitação ao local do lixão inativo. Verificouse se havia a utilização de poços de monitoramento (piezômetros) para análise das substâncias agressivas geradas nos lixões. Foram propostos como indicadores do grau de risco baixo a existência de piezômetro ea realização de coleta mensal para análise; a existência de pi ezômetro e a falta de coleta mensal para análise com grau de risco regular, e a inexistência de piezômetro e de coleta mensal, com a qualificação do grau de risco crítico.

6) Proximidade de residências

Os dados da proximidade de residências foram coletados diretamente nas áreas dos lixões, utilizando-se uma trena para conferir as distâncias. Segundo a N BR $13896^{23}$, os aterros devem possuir uma distância mínima de 500 metros dos núcleos populacionais. Foram propostos como indicadores de grau de risco baixo, com conotação estritamente geométrica, a distância acima de 500 metros; a distância entre 251 a 500 metros, com de grau de risco regular, e a distância entre 0 a 250 metros das residências, com a qualificação do grau de risco crítico.

7) Existência de cercas

Os dados de existência das cercas também foram coletados nas entrevistas ediretamentenas áreas dos lixões. Verificou-se basi camente se haviam cercas limitando o acesso de pessoas e animais. Foram propostos como indicadores degrau de risco baixo a existência de cercas de alambrado; a existência de cercas de arame, com grau de risco regular, e a inexistência de cercas, com a qualificação do grau de risco crítico.

8) Tipo de cobertura e utilização de manta de PEAD (Polietileno de Alta Densidade)

Os dados sobre o tipo de cobertura e a utilização de manta de PEAD também foram coletados no momento da entrevista e na visitação ao local do lixão inativo, sendo proposto o graus de risco baixo devido à realização de cobertura de terra e existência de manta; a existência de cobertura de terra sem a existência de manta de isolamento, com grau de risco regular, e a inexistência de cobertura de terra e de manta de isolamento, com a qualificação do grau derisco crítico.

\section{Resultados e discussão}

Os levantamentos feitos ao longo deste trabal ho revelaram que nos onze municípios pertencentes à região carbonífera há onze lixões inativos, localizados em nove municípios. Assim, há municípios com mais de um lixão inativo e municípios sem lixões inativos. Acordos realizados no passado entre municípios vizinhos permitiram o uso de um mesmo lixão. Esses acordos levam a uma configuração atual na qual o lixão, por estar inativo e "esquecido", representa maior responsabilidade e preocupação para o município que 0 abriga. Assim, o ônus é unilateral, enquanto 0 benefício foi compartilhado. Todavia, mesmo nos municípios que abrigam os lixões essa preocupação é "intermitente", o que pode ser decorrente do fato de os resíduos serem frutos de administrações passadas e de eventual inércia para com questões desse gênero, fazendo com que posicionamentos sejam assumidos para a solução dos problemas apenas quando há intervenção coercitiva dos órgãos ambientais.

0 presente inventário considera apenas os lixões conhecidos pela administração pública. Especulações acerca de antigos lo cais de deposi ção, utilizados clandestinamente ou com eventual aquiescência dos representantes passados do po- 
der público, não foram consideradas, por faltar à necessária objetividade para o desenvolvimento da pesquisa. A primeira observação evidente sobre os lixões inativos é que, em todas as cidades visitadas, não existem dados técnicos sobre os problemas gerados por esses lixões nos registros dos órgãos municipais.

Constatou-se que quatro lixões inativos estão afastados a mais de 200 metros dos corpos de água. Porém, sete lixões estão a menos de 100 metros desses corpos de água, situação que contraria as normas e que indica alto potencial de interferência na qualidade das águas. Esses sete lixões são elementos potencialmente lesivos aos corpos de água, com possibilidade de contaminação dos rios na região carbonífera, já muito comprometidos com a realidade decorrente da mineração do carvão ${ }^{8}$. Assim, há um somatório de efeitos negativos para a qualidade das águas superficiais na região (risco considerado crítico, segundo a presente classificação).

Observou-se que não há qualquer coleta e tratamento dos gases gerados em todos os lixões inativos. Como conseqüência, todo poluente gasoso é "descarregado" na atmosfera, e, no presente estudo, próximo a áreas habitadas, implicando em risco para essa população (risco considerado crítico, segundo a presente classificação).

Quanto àstécnicas dedrenagem deáguas pluviais e tratamento, dez lixões inativos não apresentam qual quer drenagem, sendo que apenas um lixão inativo possui canalização para desvio das águas superficiais. Segundo a classificação aqui proposta, há grau de risco regular nesse único lixão inativo, uma vez que foi diminuído o contato das águas pluviais com os resíduos. Nos outros dez lixões, todavia, as águas pluviais penetram e escorrem através da massa de resíduos, aumentando a vazão do chorume. N esse caso, a classificação aqui proposta indica grau de risco regular nesses lixões, porém, com impacto dire to ao meio ambiente, devido ao contato direto do resíduo ao solo. Em todos os municípios pesquisados, os lixões inativos não possuem manta de impermeabilização de fundo para impedir 0 contado do solo com os materiais poluentes gerados na decomposição dos resíduos sólidos. Constatou-se ainda que no fechamento dos onze lixões foi apenas depositado uma cobertura de terra sobre os resíduos sólidos, com classificação proposta de regular. Porém, apenas a cobertura com terra sobre os resíduos não evita os problemas gerados pela decomposição, sendo que, evidentemente há riscos ao meio ambiente e às populações vizinhas, caracterizando o problema como ambiental e de saúde pública.
Em nenhum dos onze lixões inativos existem técnicas de coleta etratamento do chorume. Esta inobservância acarreta, segundo a presente classificação, um grau de risco crítico. Como já foi mencionado, todo chorume gerado é potencial contaminante do lençol freático da região, com implicações para a saúde pública. A idade dos lixões inativos na região carbonífera é diversificada, existindo lixões inativos com idade de aproximadamente 20 anos, portanto ainda potenciais produtores de chorume.

Constatou-se que em oito lixões inativos não existem técnicas para monitoramento ambiental com utilização de piezômetros e com coleta mensal para análise. Apenas três lixões possuíam piezômetros, porém as análises não eram realizadas mensalmente para monitoramento do lençol freático. Isso implica, pela presente classificação, em grau de risco regular para os três lixões (existe equipamento sem uso). Os demais (oito) lixões inativos apresentam grau de risco crítico. A inexistência de monitoramente preventivo impede a imediata intervenção das autoridades e técnicos para solucionar eventuais problemas que podem ser gerados pela contaminação produzida pelos lixões inativos.

No aspecto de proximidade de residências, constatou-se a construção de residências e estabelecimentos sobre um dos lixões inativos. Além disso, sete lixões inativos possuem residências próximas, dentro da faixa de zero a 250 metros (risco crítico) e quatro na faixa de 251 a 500 metros de distância (risco regular). 0 risco potencial está vinculado à saúde pública, uma vez que os moradores estão próximos de vetores de doenças, de insetos e de animais peçonhentos.

No aspecto de existência de cercas, constatou-se que nove lixões inativos não possuem qualquer tipo de cerca de proteção para impedir o acesso de pessoas ou animais na localidade. Somente dois lixões inativos estão cercados com cercas de arames, implicando em grau de risco regular, pois protegem parcialmente pessoas e animais de atingirem áreas contaminadas. Os outros nove lixões inativos apresentam, segundo a classificação aqui adotada, grau de risco crítico para a saúde da população. 0 acesso de animais podetransformá-los em vetores de doenças, além do fato de crianças e adultos que se deslocam sobre os antigos lixões estarem se expondo em áreas potencialmente contaminadas pela disposição inadequada dos resíduos.

A Figura 1 resume todas as observações aqui apresentadas, especificando o grau de risco dos lixões inativos para cada um dos parâmetros arrolados no presenteestudo. O bserva-se, demodo 
geral, quetodos os resultados apontam para uma situação global crítica em todos os municípios que possuem lixões inativos. Apesar deal guns dos lixões possuírem classificação de risco regular ou baixo para um ou outro parâmetro, eles ainda expõe, na análise conjunta dos parâmetros, 0 meio ambiente e a saúde da população à potencial contaminação, demonstrando a sua fragilidade ambiental e de saúde pública. Essa avaliação é fortalecida ainda pelo fato de que nenhum dos municípios apresentava, no período dessa avaliação, mecanismos ou normas legais para a inativação dos seus lixões.

\section{Conclusões}

Neste trabalho, apresentou-se uma proposta de metodologia para avaliação de risco em lixões inativos. Espera-se que, em longo prazo, essa metodologia permita a realização de estudos comparativos, de modo a gerar um banco de in- formações sobre a situação geral dos lixões inativos existentes no território brasileiro.

No contexto do estado de Santa Catarina concluiu-se que, em todos os municípios que fazem parte da região carbonífera, há um grau de risco crítico para o meio ambiente e a saúde da população, vinculado à existência de lixões inativos. Essa conclusão se baseia em todos os parâmetros analisados, ou seja, proximidade de corpos de água superficiais, coleta e tratamento de biogás, coleta etratamento de chorume, existência de piezômetro e coleta mensal para análise, proximidade de residências, existência de cercas, tipo de cobertura e existência de manta de impermeabilização.

Nas áreas de disposição final dos resíduos, nos municípios estudados, observou-se, de forma geral, o abandono do material confinado no solo após a cobertura superficial de terra. Este fato, associado à idade dos lixões inativos, que permite inferir que ainda há possibilidade de produção de chorume, mostra que é preciso

Figura 1

Resultado dos parâmetros.

Resultado dos parâmetros

(11 lixões inativos)

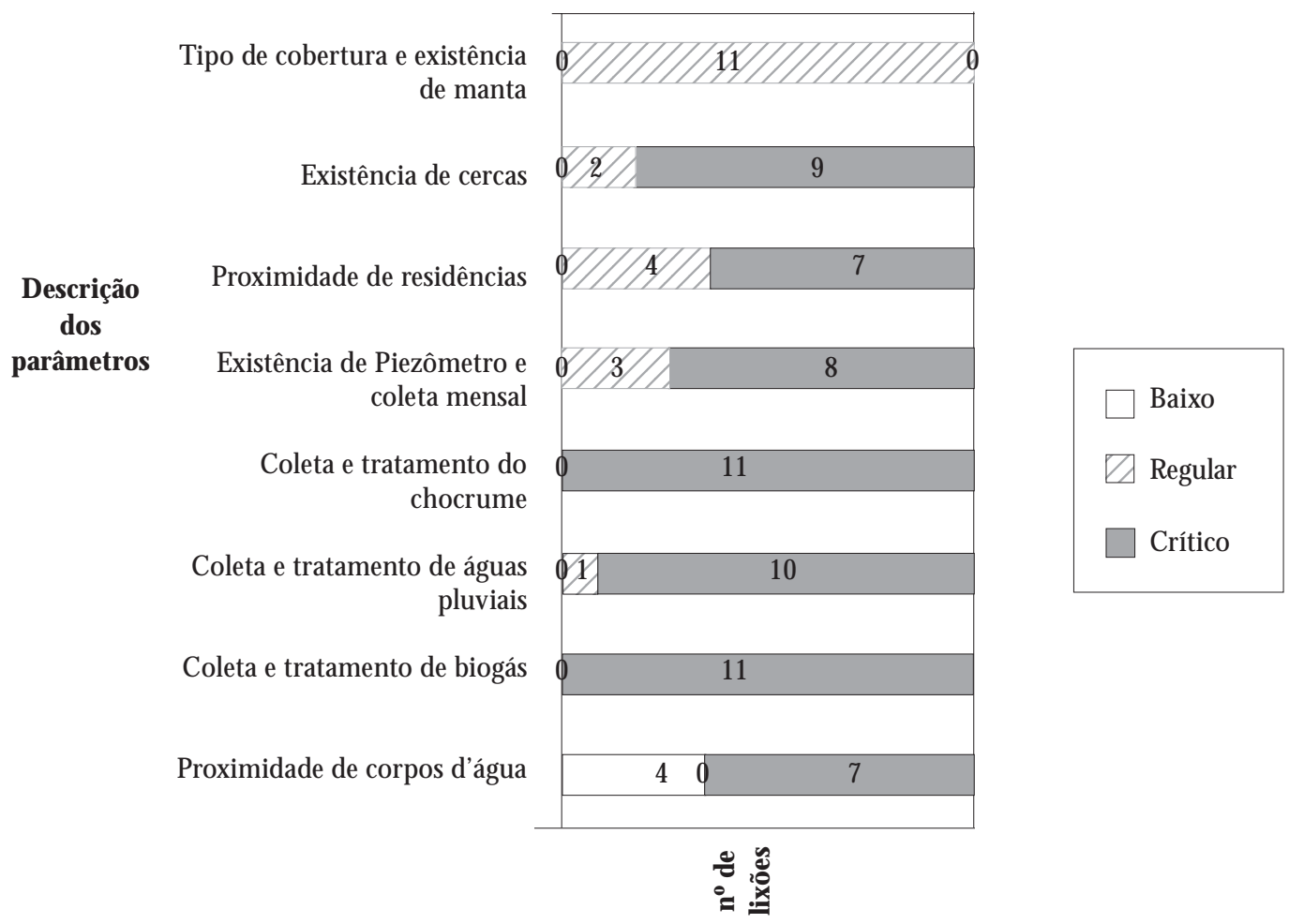


atenção especial do poder público e da própria população no monitoramento dessasáreas, uma vez que há riscos vinculados à saúde pública. $\mathrm{A}$ "inativação por simples cobertura" é uma forma de tornar o problema invisível, porém não inexistente.

Com base no exposto, cabe a ressalva de que uma legislação voltada à inativação dos lixões, bem como uma normatização técnica para mo- nitoramento das áreas utilizadas, pode auxiliar em muito as ações a serem efetuadas em nível municipal. Cremos que aqueles que se propõem a administrar nossos municípios devam assimilar o conceito de desenvolvimento sustentável, considerando as dimensões econômicas, sociais, ambientais e técnicas, visando garantir boa qualidade de vida das gerações atuais e futuras.

\section{Colaboradores}

FP Possamai trabalhou na concepção teórica, elaboração, redação final do texto, interpretação, organização e execução da pesquisa. E Viana participou como orientador durante todas as etapas da elaboração da dissertação e do artigo, com aprovação da versão para ser publicada. $\mathrm{HE}$ Schulz participou da análise dos resultados e a redação final do artigo. M M deCosta participou na elaboração da pesquisa de campo, juntamente com E Casagrande que auxiliou na coleta de materiais para redação do artigo. 


\section{Referências}

1. Cappelli S, organizador. Resíduos sólidos. Porto Ale gre: Procuradoria-Geral de Justiça; 2002.

2. Associação dos Municípios da Região Carbonífera (AM REC). Programa de recuperação ambiental e social da região carbonífera. Criciúma; 1991.

3. Ribas Junior S. Retratos de Santa Catarina. Florianópolis: Ed. do autor; 2004.

4. Zimmermann DG, Trebien DOP. Solos construídos em áreas mineradas como fundamento para recuperar o ambiente. Revista Tecnologia Ambiente 2001; 7 (1): 61-103.

5. Núcleo de Pesquisas e estatísticas socioeconômicas (NUPESE). Estudo de custo-ben efício para recuperação de áreas degradadas pela mineração de carvão. Universidade do Extremo Sul Catarinense - UNESC; 1997.

6. Estudos Ambientais Ltda. Influência da poluição da mineração de carvão no cultivo de camarão da empresa lusomar Araranguá - Santa Catarina. Porto Alegre; 1995.

7. Citadini-Zanette, V. Recuperação de áreas degradadas na região carbonífera de Santa Catarina: aspectos sucessionais e interações interespecíficas [ CD-ROM ]. In: Simpósio Nacional de Recuperação de Áreas Degradadas; 2000; Blumenau. SOBRADE; 2002.

8. Dalotto RAS. Aplicação de modelos cartográficos para simplificação prognose e decisão nos estudos ambi entais da bacia carbonífera catarinense [dissertação]. Florianópolis (SC): Universidade Federal de Santa Catarina, Florianópolis; 2000.

9. Nappo ME. Inventário florístico e estrutura de regeneração natural no sub-bosque de povoamentos homogê neos de M imosa sacabrella Bentham, implantados em áreas mineradas, em Poços deCalda, M inas Gerais [dissertação]. Larvas (M G): Universidade Federal de Larvas; 1999.

10. M achado PAL. Direito ambiental brasileiro. 10ª ed. São Paulo: Malheiros; 2002.

11. Sissino CLS, Oliveira RM. Resíduos sólidos, ambientee saúde: uma visão multidisciplinar. Rio de Janeiro: Fiocruz; 2000
12. Pacheco JR, Zamora-Peralta, Patrício G. Integração de processos físico-químicos e oxidativos avançados para remediação de percolado de aterro sanitário (chorume). Revista deEngenharia Sanitária eAmbiental 2004; 9 (4): 306-311.

13. Instituto Brasileiro de Geografia e Estatística (IBGE). Pesquisa nacional de saneamento básico. Rio de Janeiro: Instituto Brasilei ro de Geografia eEstatística; 2002.

14. Jucá JFT. Disposição Final dos resíduos sólidos urbanos no Brasil [CD-ROM ]. Anais do Congresso Brasileiro de Geotecnia Ambiental - REGEO'2003; Porto Alegre; 2003.

15. Fernandes JUJ. Lixo. Limpeza pública urbana; gestão de resíduos sólidos sob o enfoque do direito administrativo. Belo Horizonte: Del Rey; 2001.

16. Hamada J. Estimativas de geração e caracterização do chorume em aterros sanitários. Tema III-055. Anais do $19^{\circ}$ Congresso Brasileiro de Engenharia Sanitária eAmbiental; 1999.

17. Rodrigues FLR, Gravinatto VM . Lixo: de onde vem? Para onde vai. São Paulo: M oderna; 1997.

18. Rocca ACC, et al. Resíduos sólidos industriais. 2ª ed. São Paulo: CETESB; 1993.

19. Associação Brasileira de Normas Técnicas. N BR 8419: A presentação de projetos de aterros sanitários de resíduos sólidos urbanos. Rio de Janeiro: ABNT; 1984.

20. Associação Brasileira de Normas Técnicas. N BR 13896: Fixa condições mínimas exigíveis para projetos, implantação e operação de aterros de resíduos sólidos não perigosos. São Paulo: ABNT; 2002.

21. Grizzi ALE. A agenda 21 nacional e os resíduos sólidos. Revista de Direitos Difusos. Gestão de Resíduos Sólidos II 2002; 2 (14): 1851-1859.

Artigo apresentado em 18/07/2005

Aprovado em 20/07/2006

Versão final apresentada em 20/07/2006 